\author{
Tomasz SAMBORSKI ${ }^{1}$ \\ Andrzej ZBROWSKI ${ }^{2}$
}

\title{
STANOWISKO DO BADANIA ODPORNOŚCI PASZPORTÓW NA PRZEGLĄDANIE
}

\begin{abstract}
W pracy przedstawiono metodę i stanowisko do badania odporności wielostronicowego dokumentu (paszportu) na wyrwanie z grzbietu kartki wskutek wielokrotnego składania lub przeglądania. Metoda badania, zgodna z zaleceniami Międzynarodowej Organizacji Lotnictwa Cywilnego (ICAO) odnośnie wdrażania środków zabezpieczania paszportów i zawartych w nich danych, polega na cyklicznym obracaniu kartki lub dokumentu w trakcie testu wokół osi grzbietu dokumentu pomiędzy określonymi położeniami kątowymi. Obracaniu towarzyszy, odzwierciedlająca charakter warunków użytkowania, stała siła prostopadła do osi obrotu zależna od długości nieruchomej krawędzi kartki. Zaprezentowano rozwiązania konstrukcyjne podstawowych układów wykonawczych, istotnych z punktu widzenia poprawności realizowanych procedur oraz ergonomii użytkowania. Układ sterowania stanowiskiem oparty na programowalnym sterowniku PLC pozwala na realizację badań w szerokim zakresie zmienności podstawowych parametrów decydujących o końcowej ocenie wyrobu. Wprowadzanie parametrów badań (częstość, liczba cykli), prowadzenie testów kalibracji siły oraz położenia układów wykonawczych jest realizowane $\mathrm{z}$ wykorzystaniem wielofunkcyjnego panelu operatorskiego. Zakres parametrów użytkowych urządzenia, wykraczający poza wynikające $\mathrm{z}$ istniejących unormowań, pozwala na jego zastosowanie nie tylko do bieżącej kontroli procesu produkcji lub kontroli dostaw, ale również do prowadzenia prac rozwojowych związanych z prototypowaniem nowych rozwiązań w obszarze wytwarzania wielostronicowych dokumentów. Wykorzystanie opracowanego urządzenia w obszarze badań trwałości dokumentów, szczególnie paszportów, prowadzonych przez upoważnione służby państwowe przyczyni się do podniesienia poziomu bezpieczeństwa związanego m.in. z ruchem transgranicznym.
\end{abstract}

Słowa kluczowe: dokument, trwałość, badanie, kartkowanie

\section{Wprowadzenie}

Rosnąca nieustannie liczba osób przekraczających granice państw stawia przed narodowymi służbami zadanie prowadzenia szybkiej i skutecznej identy-

${ }^{1}$ Tomasz Samborski, Instytut Technologii Eksploatacji - Państwowy Instytut Badawczy, ul. Pułaskiego 6/10, 26-600 Radom

2 Autor do korespondencji/corresponding author: Andrzej Zbrowski, Instytut Technologii Eksploatacji - Państwowy Instytut Badawczy, ul. Pułaskiego 6/10, 26-600 Radom, tel.: (48) 3649243; fax: (48) 3644760, e-mail: andrzej.zbrowski @itee.radom.pl 
fikacji [1]. Dokumentem, który umożliwia identyfikację podróżnych, jest odpowiednio zabezpieczony paszport. Międzynarodowa Organizacja Lotnictwa Cywilnego (ICAO), współpracując z krajowymi instytucjami zajmującymi się emisją i produkcją paszportów, generuje zalecenia $[2,3]$ odnośnie wdrażania środków zabezpieczania paszportów i zawartych w nich danych oraz wprowadzania w tym zakresie odpowiedniego prawa i uregulowań normatywnych. Zgodnie $\mathrm{z}$ zaleceniami ICAO paszport musi być odporny m.in. na narażenia związane $\mathrm{z}$ użytkowaniem (noszenie $\mathrm{w}$ kieszeni, przeglądanie, stemplowanie, dokonywanie zapisów długopisem). Spełnienie tych wymagań wymusza na producentach posiadanie odpowiedniej aparatury badawczo-testowej przystosowanej do prowadzenia badań zgodnie $\mathrm{z}$ odpowiednimi metodami, według ustalonych procedur [4]. Paszport jest dokumentem w formie książeczki o wymiarach $125 \times 88 \mathrm{~mm}$, zawierającym kartę do personalizacji oraz kilkadziesiąt kart wizowych. Połączenie okładki z poszczególnymi kartkami (składkami) jest najczęściej zrealizowane w technologii szycia nitką introligatorską - lnianą, bawełnianą lub syntetyczną (rys. 1.). Zastosowana technologia oraz użyte materiały w bezpośredni sposób rzutują na odporność dokumentu na wyrwanie z grzbietu kartek wskutek wielokrotnego składania czy przeglądania.

a)
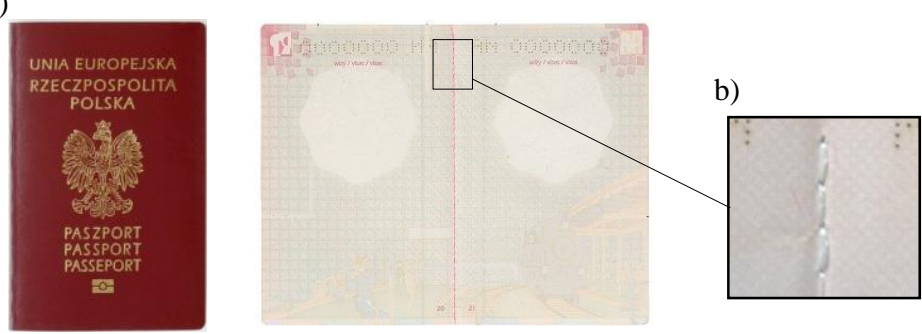

Rys. 1. Książeczka paszportowa (a) wraz z widocznym szyciem (b)

Fig. 1. Passport (a) with visible stitch (b)

\section{Metoda badania}

Testowi kartkowania poddaje się dokumenty utworzone $\mathrm{z}$ wielu kartek w postaci książeczki. Test symuluje obciążenie kartek książeczki paszportowej w trakcie kontroli związanej z przekraczaniem granic państw. Jest to czynność wykonywana często $\mathrm{w}$ pośpiechu, w warunkach polowych i niezbyt starannie. Zgodnie z procedurą badań dokument jest mocowany w uchwycie, a kartka poddawana testowi jest obciążana siła rozciagającą - wyrywającą oraz obracana cyklicznie o kąt $180^{\circ}$ (rys. 2.). Urządzenie do testu kartkowania powinno posiadać uchwyt ściskający dokument oraz zacisk kartki wykonujący wahadłowy ruch roboczy, obciążający jednocześnie kartkę określoną siłą. Pionową osią obrotu jest wewnętrzna krawędź kartki, a wektor siły jest skierowany prostopadle 
do osi. Parametrami zmiennymi badania są wartość siły i liczba cykli ruchu wahadłowego. Normatywna procedura zakłada badanie książeczki paszportowej w następujących warunkach [3]:

- częstość ruchu oscylacyjnego $-0,5 \mathrm{~Hz}$,

- kąt obrotu $- \pm 90^{\circ}$,

- siła obciążająca - $1 \mathrm{~N} / \mathrm{cm} \pm 25 \%$ (siła przypadająca na jednostkę długości kartki),

- liczba cykli przeginania - 1000 cykli.

a)

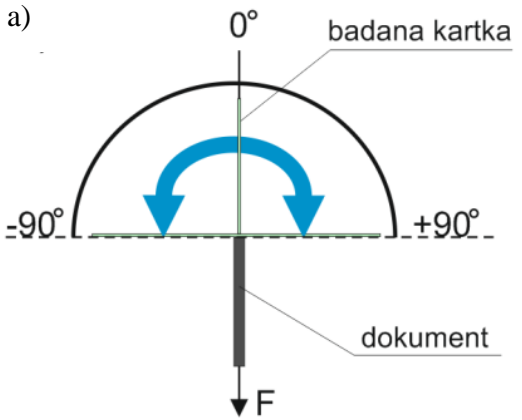

b)

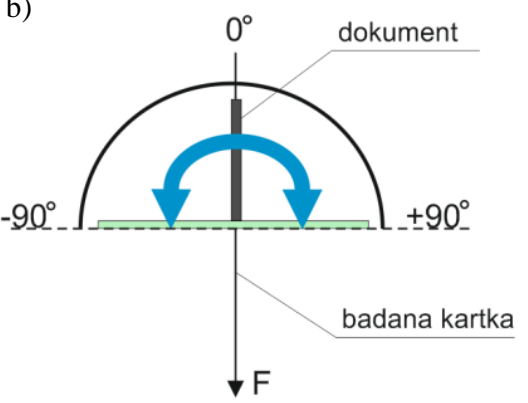

Rys. 2. Sposób badania dokumentu: a) jest obracana badana kartka, b) jest obracany badany dokument

Fig. 2. A method of document test: a) a page is turned, b) a document is turned

\section{Budowa stanowiska}

Opracowane metody i procedury badania odporności dokumentów na przeglądanie zostały wykorzystane do zdefiniowania wymagań konstrukcyjnych i funkcjonalnych urządzenia testowego. Określono funkcje, parametry techniczne oraz zasadę działania poszczególnych podzespołów urządzenia (rys. 3.). Przy ustalonej średnicy $d$ kół przekładni pasowej zmiana długości $a$ korbowodu decyduje o wielkości skoku $s$, a w konsekwencji o wartości wychylenia kątowego kartki połączonej z kołem pasowym. Przyjęte wymagania pozwoliły na zdefiniowanie podstawowych parametrów charakteryzujących urządzenie testowe:

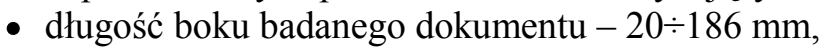

- zakres regulacji siły $-1 \div 40 \mathrm{~N}$,

- kąt obrotu badanej kartki - $0 \div \pm 90^{\circ}$,

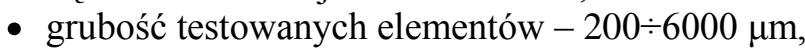

- częstość ruchu oscylacyjnego $-0,2 \div 1 \mathrm{~Hz}$,

- liczba cykli obciazżania - do 10000 ,

- zasilanie $-230 \mathrm{~V}, 50 \mathrm{~Hz}$,

- liczba jednorazowo badanych dokumentów - 1 .

Na podstawie przyjętych założeń konstrukcyjnych opracowano model wirtualny testera z wykorzystaniem pakietu Autodesk Inventor Professional. Opra- 
cowany model pozwolił na przeprowadzenie szeregu analiz kinematyki układów ruchowych oraz obliczeń metodą MES naprężeń w wybranych węzłach konstrukcyjnych. Model 3D umożliwił również przeprowadzenie oceny zaproponowanego rozwiązania pod kątem ergonomii obsługi. Konstrukcje nośną testera (rys. 4.) tworzy system profili aluminiowych $\mathrm{z}$ wydzielonymi trzema modułami

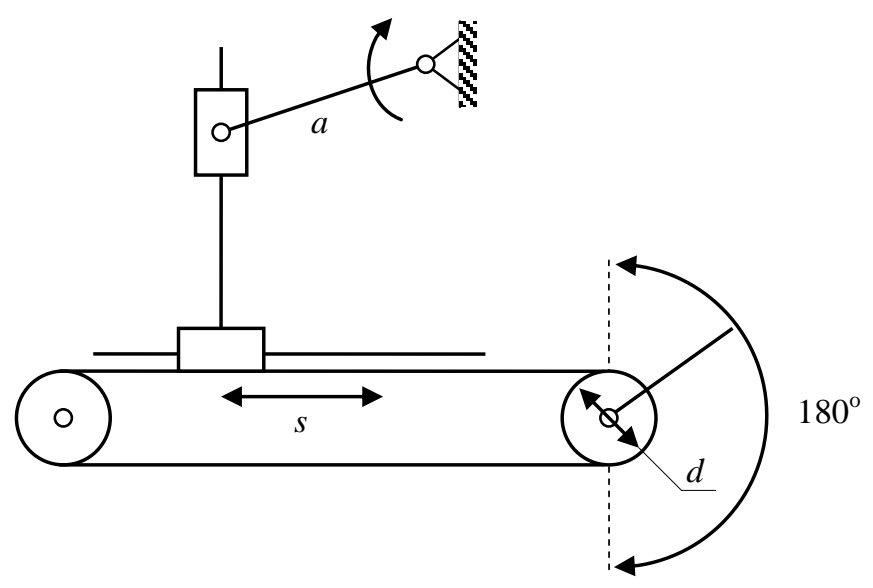

Rys. 3. Schemat kinematyczny testera: $d$-średnica koła pasowego, $s$ - skok, $a$ - regulowana długość korbowodu

Fig. 3. Kinematic diagram of the tester: $d$ - belt wheel diameter, $s$ - stroke, $a$ - adjustable length of a connecting rod

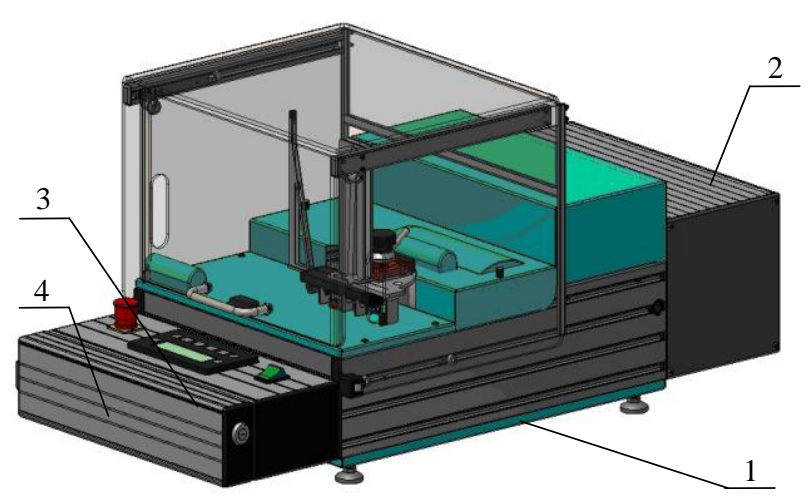

Rys. 4. Model urządzenia do testowania wytrzymałości kartek dokumentów na wyrwanie pod różnymi kątami: 1 - moduł układów wykonawczych, 2 - moduł systemu sterowania, 3 panel operatorski, 4 - kaseta zespołu kalibracji siły

Fig. 4. Model of the device for tear-out endurance tests for document pages conducted at different angles: 1 - executive 
system module, 2 - control system module, 3 - control panel,

4 - cassette of force calibration assembly

zawierającymi: układy wykonawcze (1), elementy systemu sterowania (2), panel operatorski (3), kasetę z czujnikiem kalibracji siły (4). Głównym zespołem, bezpośrednio odpowiedzialnym za realizację procedury badawczej, jest wielofunkcyjna głowica (rys. 5.) składająca się $\mathrm{z}$ dwóch zespołów szczęk: stałych (1) i obrotowych (2).

Rys. 5. Wielofunkcyjna głowica testera do badania kart dokumentu na wyrywanie: 1 - zespół szczęk stałych (mocujących), 2 - zespół szczęk obrotowych, 3 - badany dokument

Fig. 5. Multifunctional tester head for testing pages endurance to tear-out: 1 - set of permanent jaws, 2 - set of rotating jaws, 3 - tested document

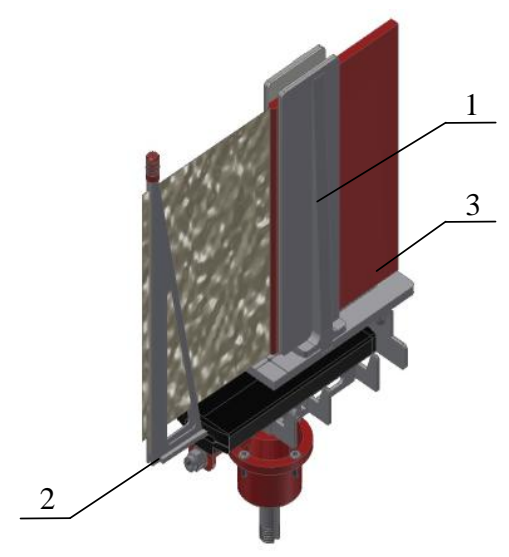

Zespół szczęk stałych (rys. 6.) służy do zamocowania paszportu (kartki) pomiędzy dwoma rozsuwającymi się symetrycznie, wyposażonymi w nakładki cierne (3), szczękami (2). Rozchylanie szczęk (2) jest realizowane przez obrót dźwigni (5) wprawiającej w ruch obrotowy dwa (niewidoczne na rys. 6.) przeciwbieżne mimośrody współpracujące ze szczękami (2) uchwytu. Unieruchomienie książeczki w zespole odbywa się poprzez obrót dźwigni (5), której bieżąca pozycja jest ustalana za pomocą umieszczonego powyżej pokrętła (6). Zespół szczęk ruchomych (rys. 7.) jest odpowiedzialny za unieruchomienie badanej kartki (dokumentu) celem nadania jej ruchu wahadłowego oraz wywarcie określonej siły wyrywającej.

Rys. 6. Zespół szczęk stałych: 1 - stół uchwytu dokumentu, 2 - szczęka, 3 - nakładka cierna, 4 - prowadnica szczęk, 5 -dźwignia zaciskowa, 6 - pokrętło blokujące

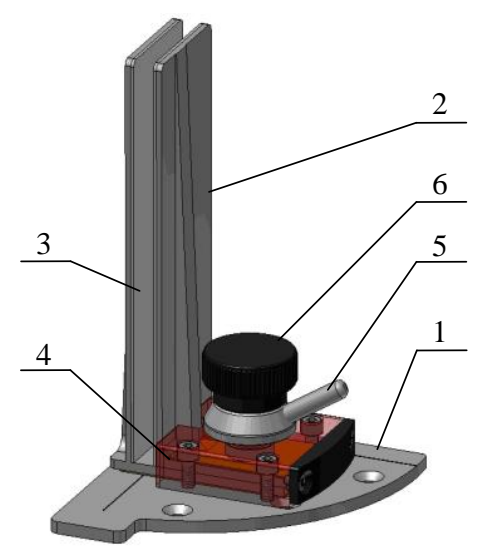


Fig. 6. Set of permanent jaws: 1 - document grip stand, 2 - jaw, 3 - friction strap, 4 - jaws slide, 5 - clamping lever, 6 - blocking knob

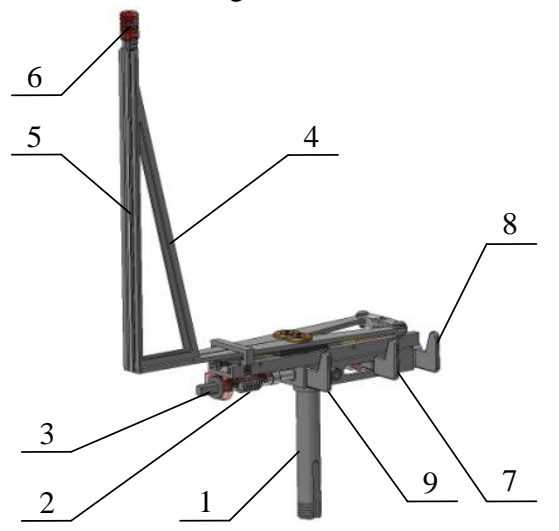

Rys. 7. Zespół szczęk ruchomych: 1 - wałek napędowy, 2 - sprężyna napinająca, 3 - nakrętka regulacyjna, 4 - szczęka, 5 - nakładka cierna, 6 - nasadka, 7 - dźwignia sterowania zaciskiem karty, 8 - dźwignia zamocowania karty, 9 - dźwignia uwolnienia karty

Fig. 7. Set of moveable jaws: 1 - drive shaft, 2 - tension spring, 3 - regulation nut, 4 - jaw, 5 - friction strap, 6 - cap, 7 - lever controlling leaf clamp, 8 leaf fixing lever, 9 - leaf release lever

Ustalenie poddawanej obciążeniu karty następuje pomiędzy dwiema szczękami nożycowymi (4) z nakładkami ciernymi (5), napędzanymi przesuwnymi dźwigniami powodującymi zamocowanie lub zwolnienie karty. Zacisk karty odbywa się przez ściagnięcie środkowej (7) i tylnej (8) dźwigni. Zwolnienie karty zapewnia względne przesunięcie dźwigni środkowej (7) i przedniej (9). W celu zapewnienia stałego zacisku, po zaciśnięciu kartki swobodne końce szczęk (4) są spinane specjalną nasadką (6). Ze względu na konieczność regulacji siły wyrywającej zespół jest wyposażony w kalibrowaną sprężynę (2) służącą do elastycznego naciagnięcia karty podczas testu.

W celu przeprowadzenia nastaw obciążenia (rys. 8.) poprzez regulację napięcia sprężyny (7) należy w zespole szczęk stałych (2) zacisnąć korpus zespołu kalibrującego (1) z jednoczesnym umieszczeniem zaciśniętych szczęk obrotowych (3) w uchwycie pomiarowym (4). Przetworzony sygnał z przetwornika siły (5), umieszczonego w zespole kalibrującym (1), jest wyświetlany na ekranie panelu operatorskiego w postaci bieżącej siły, której wartość reguluje się za pomocą nakrętki (6) napinającej sprężynę (7). Ruch wahadłowy zespołu szczęk

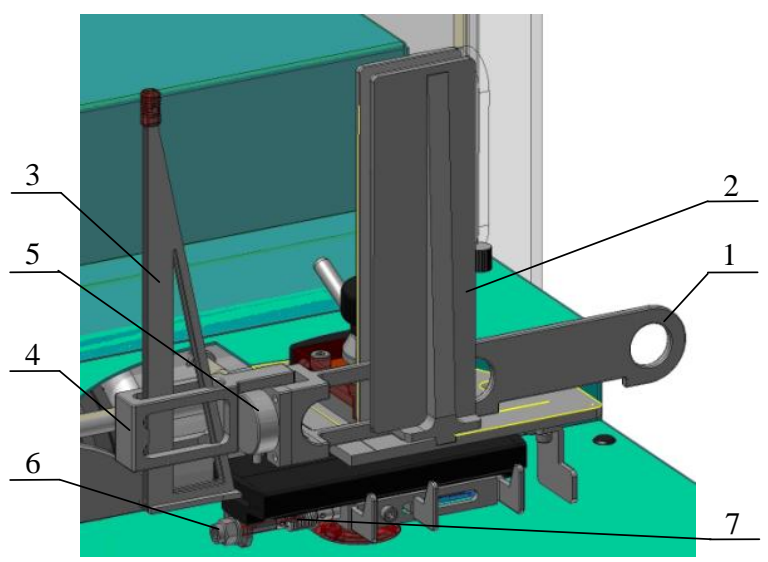

Rys. 8. Kalibracja sprężyny naciągowej: 1 - zespół kalibrujący, 2 zespół szczęk stałych, 3 - zespół szczęk obrotowych, 4 - uchwyt pomiarowy, 5 - przetwornik siły, 6 nakrętka, 7 - sprężyna napinająca

Fig. 8. Tension spring calibration: 1 - calibration set, 2 - set of permanent jaws, 3 - set of rotating 
jaws, 4 - measurement holder, 5 power transducer, 6 - nut, 7 - tension spring

obrotowych (9) wielofunkcyjnej głowicy badawczej jest realizowany za pomocą synchronicznej przekładni, której pas (7) jest połączony z wózkiem (6) poruszającym się rewersyjnie po prowadnicach tocznych (rys. 9.). Ruch posuwistozwrotny wózka wymusza obracająca się tarcza mimośrodu (2) z rolką (4), współpracująca z jarzmem (5) połączonym z wózkiem (6). Zmiana odległości osi rolki wodzącej (4) od osi obrotu, napędzanej silnikiem asynchronicznym (1) tarczy (2), umożliwia regulację wychyleń szczęk obrotowych (9) głowicy od wartości bliskiej zeru do wymaganych $\pm 90^{\circ}$.

Rys. 9. Model mechanizmu napędu: 1 - motoreduktor, 2 - tarcza mimośrodu, 3 - ramię mimośrodu, 4 - rolka wodząca, 5 - jarzmo, 6 wózek, 7 - pas zębaty, 8 - zespół szczęk stałych, 9 - zespół szczęk obrotowych

Fig. 9. Model of the drive mechanism: 1 - gearmotor, 2 - eccentric disc, 3 - eccentric arm, 4 crosshead roller, 5 - yoke, 6 - cart, 7 - cogbelt, 8 - permanent jaws set, 9 - rotating jaws set

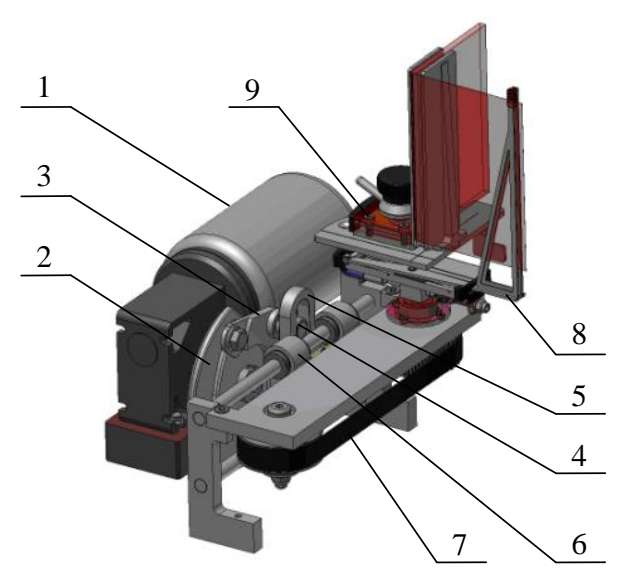

\section{Prototyp stanowiska}

Na podstawie opracowanego modelu wirtualnego urządzenia zbudowano prototyp stanowiska do badania odporności paszportów na przeglądanie (rys. 10.). System kontrolno-pomiarowy urządzenia powstał $\mathrm{z}$ wykorzystaniem sterownika PLC rodziny Twido $\mathrm{w}$ wersji modułowej, programowany $\mathrm{w}$ środowisku TwidoSuite. Wizualizację oraz komunikację sterownika PLC z operato-

a)

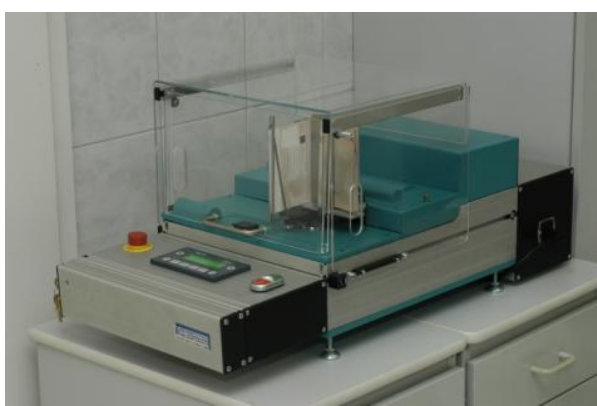

b)

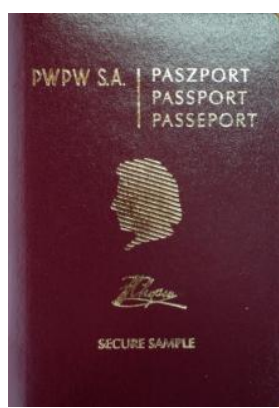


Rys. 10. Widok stanowiska (a) oraz dokumentu testowego (b)

Fig. 10. View of test stand (a) and the tested document (b)

rem zapewnia terminal operatorski (4, rys. 11.) rodziny Magelis, oprogramowany w środowisku Vijeo-Designer Lite. Informacje o stanie urządzenia są wyświetlane $\mathrm{w}$ formie komunikatów na odpowiednich panelach, dotyczących np.: wyboru rodzaju wykonywanego testu, stanu zaawansowania testu, możliwości wyboru nastaw.

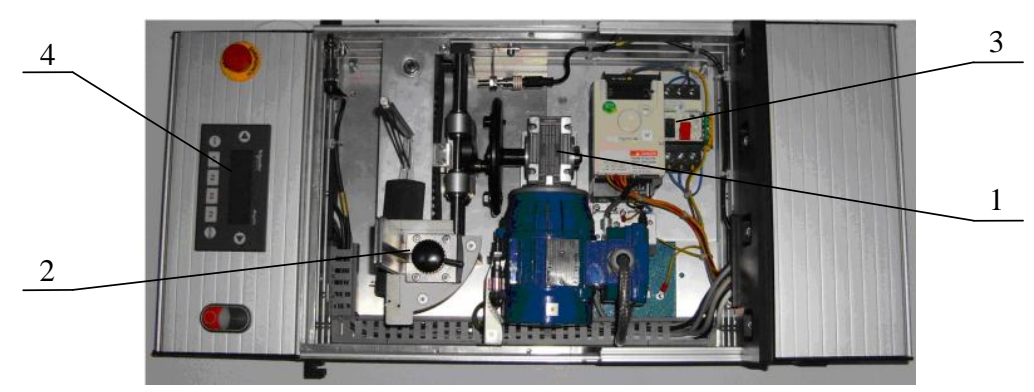

Rys. 11. Widok urządzenia (bez osłon): 1 - zespół napędowy, 2 - głowica wielofunkcyjna, 3 - elementy systemu sterowania, 4 - panel operatorski

Fig. 11. View of the device (casing taken off): 1 - drive unit, 2 - multifunctional head, 3 - elements of the control system, 4 - control panel

W celu weryfikacji opracowanej aparatury badawczo-testowej próbom porównawczym poddano książeczki testowe (rys. 10b), na wykonanym egzemplarzu i urządzeniu komercyjnym znajdującym się w dyspozycji Polskiej Wytwórni Papierów Wartościowych. Za pomocą prototypu przebadano 14 ksiązeczek paszportowych. Dla każdej książeczki przebadano jedną stronę, poddając ją oddziaływaniu 1000 cykli obciążeniowych. Wyniki testów nie wykazały różnic pomiędzy rezultatami uzyskanymi na dwóch różnych stanowiskach badawczych. W obu przypadkach wszystkie książeczki spełniły stawiane wymagania. Test nie spowodował uszkodzeń mechanicznych okładki ani stron wizowych.

\section{Podsumowanie}

Zbudowane w Instytucie Technologii Eksploatacji Państwowego Instytutu Badawczego w Radomiu stanowisko badawcze spełnia wszystkie wymagania stawiane urządzeniom przeznaczonym do prowadzenia badań testowych. Zakres parametrów użytkowych urządzenia, wykraczający poza wynikające z istniejących unormowań, pozwala na jego zastosowanie nie tylko do bieżącej kontroli procesu produkcji lub kontroli dostaw, ale również do prowadzenia prac rozwojowych związanych z prototypowaniem nowych rozwiązań w obszarze wytwarzania wielostronicowych dokumentów. Sprawny system badań trwałości dokumentów, szczególnie paszportów, z wykorzystaniem nowoczesnego instrumen- 
tarium badawczego przyczyni się do podniesienia poziomu bezpieczeństwa związanego m.in. z ruchem transgranicznym.

\title{
Literatura
}

1. Neuby B.L., Rudin E.: Radio Frequency Identification: A panacea for governments? Public Organization Review, no. 8 (2008), pp. 329-345.

2. Doc. 9303 Machine Readable Travel Documents. ICAO, $6^{\text {th }}$ ed., 2006.

3. Machine Readable Travel Documents. Technical Report: Durability of Machine Readable Passports Version 3.2, ICAO 2006.

4. Kozioł S., Zbrowski A., Samborski T., Wiejak J.: Koncepcja systemu testowania połączeń montażowych $\mathrm{w}$ dokumentach $\mathrm{z}$ zabezpieczeniem elektronicznym. Technologia i Automatyzacja Montażu, nr 4 (2010) s. 6-9.

Praca naukowa wykonana w ramach realizacji Projektu Badawczego Rozwojowego $\mathrm{nr}$ OR00003909 pn. „System i pilotowa implementacja zabezpieczeń elektronicznych zawierajacych układy RFID”.

\section{THE STAND FOR TESTING PASSPORT ENDURANCE TO THUMBING}

\begin{abstract}
A bstract
The article presents a method and a stand for testing the endurance of a passport's pages to tear-out resulting from their repeated thumbing and turning. The test method complies with the ICAO's requirements concerning the implementation of security measures for ID documents and data stored in them, and it consists in a repeated page or document turning around the axis of the document edge between predefined angular positions. The turning is accompanied by the presence of a constant force, perpendicular to the rotation axis and dependent on the length of the immovable page edge. The authors show structural solutions that are crucial from the point of view of proper execution of the test procedure, user ergonomics and basic executive systems. The stand control system, based on a programmable PLC controller, enables the tests to be conducted for a wide range of changeability of basic parameters deciding on the final assessment of the product. A multifunctional control panel enables the parameters to be set, the calibration tests to be performed and the executive systems to be adjusted. The parameter range of the device, significantly exceeding the current norms, allows for its application in $R \& D$ tasks concerning prototyping of new solutions in the area of multilayered electronically tagged document development. The practical application of the device in document endurance tests conducted by authorized institutions may increase the security level connected i.e. with transborder migration.
\end{abstract}

Keywords: document, endurance, test, thumbing

DOI: $10.7862 / \mathrm{rm} .2013 .6$

Otrzymano/received: 25.02 .2013

Zaakceptowano/accepted: 2.04.2013 